\title{
THE ROLE OF NIOBIUM AND OTHER REFRACTORY ELEMENTS
}

\section{IN SUPERALLOYS}

\author{
J. K. Tien, John P. Collier and G. Vignoul \\ Center for Strategic Materials \\ Henry Krumb School of Mines \\ Columbia University \\ New York, N.Y. 10027
}

Refractory elements are important alloying additions in both nickel-base and ironnickel-base superalloys. They are responsible for the increased high temperature mechanical properties present in current superalloy systems.

This paper presents the results from ongoing research programs which study the effectiveness of niobium and tantalum in various nickel-base superalloys and ironnickel-base superalloy INCONEL 718. This work not only shows the significance of niobium and tantalum as alloying additions in current superalloys, but also the necessity of these additions in the design of future superalloys demanding greater strength and temperature resistance. \footnotetext{
Superalloy 718 -Metallurgy and Applications
Edited by E.A. Loria

The Minerals, Metals \& Materials Society, 1989
} 


\section{Introduction}

It has long been established that nickel-base and iron-nickel-base superalloys are "super" because they are strengthened by a dispersion of fine and coherent gamma-prime $\left(\gamma^{\prime}\right)$ and at times by gamma double-prime $\left(\gamma^{\prime \prime}\right)$ precipitates within the gamma $(\gamma)$ phase. These phases impart reasonably high tensile and creep strength at elevated temperatures while maintaining adequate ductility, fracture toughness, and fatigue properties. These precipitates are formed by the precipitation reaction of $\mathrm{Ni}$ with $\mathrm{Al}$ and $\mathrm{Ti}$ or, in the case of the iron-nickel-base superalloy (IN718), $\mathrm{Nb}$ and $\mathrm{Ti}(1,2)$.

The refractory elements, $\mathrm{Nb}$ and $\mathrm{Ta}$, perform strengthening functions in both the $\gamma$ and the precipitating $\gamma^{\prime}$ and $\gamma^{\prime \prime}$ phases. These elements can behave somewhat differently as carbide formers. They are also known to affect corrosion resistance and alloy stability. Both elements are bcc metals, and are highly misfitting in the fcc $\mathrm{Ni}$ lattice; consequently giving rise to their well deserved reputation as potent solid-solution strengthening elements in the $\gamma$ as well as in the precipitating phases. Tantalum and niobium are known to partition into the strengthening $\gamma^{\prime}$ and $\gamma^{\prime \prime}$ phases, and are also MC- type carbide formers (3-5). Furthermore, to varying degrees these elements increase incipient melting and solidus temperatures. This results in not only a higher and broader temperature range for solutionization and homogenization, but also in segregation problems during the primary vacuum refining and melting process (VIM) and during such secondary structures refining melt processes as VAR and ESR. However, Ta is known to decrease the tendency for freckling during the directional solidification of turbine blades (6).

The detailed roles of refractory elements in superalloys are not well understood. In particular, the science-based technology for substituting one refractory element for another does not exist. For example, it is not known whether $\mathrm{Ta}$ and $\mathrm{Nb}$ are better strengtheners than other refractory elements, e.g., $\mathrm{W}$ and Mo. In addition, it is not known whether the large degree of misfit between the $\gamma$ and precipitating phases, due to refractory element additions, affects such properties as strain strengthening and $\gamma^{\prime}$ and $\gamma^{\prime \prime}$ coarsening kinetics, which is an issue with respect to long term applications. In order to design and develop more enhanced superalloys, as well as to conserve on the more expensive and less abundant alloying elements, a better understanding on the role of these refractory elements on the mechanical and microstructural properties in superalloys is necessary.

This paper will present the ongoing research which addresses such questions. This paper will discuss not only the effects of refractory alloying elements in nickel-base superalloys, but also in the high niobium containing ironnickel-base superalloy IN718, which represents roughly one-third of all superalloy sales, with emphasis on the development of a more microstructurally and thermally stable alloy. Not included in this paper is the situation with respect to the proprietary monocrystalline superalloys with high tantalum contents. However, the 
scientific opinions discussed below are generally applicable.

\section{The role of refractory elements in nickel-base superalloys}

Recent fluctuations in the supply of some strategic elements used in superalloys; i.e., elements in which the United States is import reliant, has resulted in the creation of government funded research programs aimed at studying the feasibility of replacing these strategic elements with more accessible refractory elements; e.g., molybdenum. The purpose of these programs is to study the characteristic and synergistic effects of alloying with various refractory elements on the mechanical, corrosive and microstructural properties in nickel-base superalloys with the intention of reducing the United States' dependence on these elements by substituting them with less strategic elements while maintaining or improving on the existing properties of these alloys.

One such program, which is sponsored by the United States Office of Naval Research, deals with understanding the roles of $\mathrm{Ta}, \mathrm{Nb}, \mathrm{W}$, and Mo in superalloys in an effort to replace the import reliant elements, $\mathrm{Ta}, \mathrm{Nb}$, and $\mathrm{W}$, with the "sourcesafe" refractory element, molybdenum, which the United States mines. In what follows is a brief review of our findings with an emphasis on the roles of $\mathrm{Ta}$ and $\mathrm{Nb}$. A complete summary of our findings can be found in the articles published under this program $(7,8)$.

When choosing an alloying system to study the role of refractory elements in nickel-base superalloys, one can either, (A) continue to investigate existing refractory metals containing superalloys in detail and compare them with each other, (B) study simpler ternary or quartenary systems, or (C) select representative alloys and systematically substitute the refractory elements with each other in each alloy. We had chosen as the research strategy approach (C), since (A) will not isolate the effects of individual elements and $(B)$ will never yield the synergistic effects, which only studies of real systems can provide.

The two representative commercial nickel-base superalloys we had chosen to study were B1900 and IN738, see Table I. The B1900 alloys allow for a simple and direct comparative study between Mo and $\mathrm{Ta}$ on the mechanical and microstructural properties in this alloy system. The more complex IN738 alloy system which contains the four refractory elements, $\mathrm{Ta}, \mathrm{Nb}, \mathrm{W}$ and Mo, not only allows one to compare the effects of each refractory element on these properties, but also reveals any type of synergistic effect arising between the different refractory elements.

In what follows are some of the more pertinent results from the mechanical and microchemistry data. The effect of these substitutions on the alloys' incipient solidus, liquidus, gamma prime solvus and volume fraction is given in Table II. Table III presents $\gamma / \gamma^{\prime}$ partitioning behavior of each refractory element in the two alloy systems. This data was obtained from a STEM-EDS study of the 
microchemistry of the $\gamma, \gamma^{\prime}$ and carbide phases. Tables IV and $V$ give the room temperature tensile and $760^{\circ} \mathrm{C}$ creep/stress rupture properties of these alloys.

Table 1. Chemical Composition of the Alloys (Wt \%)

\begin{tabular}{|c|c|c|c|c|c|c|c|c|c|c|}
\hline Alloy & Ia & $\underline{\mathrm{Nb}}$ & $\underline{w}$ & $\underline{\text { Mo }}$ & $\underline{\text { Al }}$ & Ii & Cr & Co & $\underline{\mathrm{C}}$ & $\underline{\mathrm{Ni}}$ \\
\hline B1900 & 3.96 & 0.02 & 0.10 & 5.92 & 5.84 & 0.97 & 8.39 & 10.06 & 0.10 & bal \\
\hline \multirow[t]{2}{*}{$\mathrm{Mo} / \mathrm{Ta}$} & 0.01 & 0.03 & 0.06 & 8.20 & 5.90 & 1.00 & 8.10 & 10.30 & 0.10 & bal \\
\hline & \multicolumn{8}{|c|}{ (Both alloys contain 0.015 pct B and 0.10 pct $\mathrm{Zr}$ ) } & & \\
\hline IN738 & 1.71 & 0.86 & 2.61 & 1.74 & 3.33 & 3.56 & 16.08 & 8.42 & 0.16 & bal \\
\hline MoN & 1.70 & 1.00 & 0.10 & 3.10 & 3.40 & 3.30 & 16.20 & 8.70 & 0.17 & bal \\
\hline $\mathrm{Mo} / \mathrm{Ta}$ & 0.10 & 0.94 & 2.53 & 2.65 & 3.51 & 3.43 & 16.20 & 8.50 & 0.18 & bal \\
\hline \multirow[t]{2}{*}{$\mathrm{Mo} / \mathrm{Nb}$} & 1.68 & 0.02 & 2.53 & 2.59 & 3.39 & 3.34 & 15.91 & 8.57 & 0.17 & bal \\
\hline & \multicolumn{10}{|c|}{ (All four alloys contain $\leq 0.011$ pct B and 0.10 pct $Z r$ ) } \\
\hline
\end{tabular}

Table ll. Gamma Prime Fractions and Differential Thermal Analysis Results

\begin{tabular}{ccccc}
\hline & $\begin{array}{c}\text { GP } \\
\text { Fraction } \\
(\text { At \%) }\end{array}$ & $\begin{array}{c}\text { GP } \\
\text { Solvus } \\
\left(^{\circ} \mathrm{C}\right)\end{array}$ & $\begin{array}{c}\text { Incipient } \\
\text { Solidus } \\
\left.\boldsymbol{(}^{\circ} \mathrm{C}\right)\end{array}$ & $\begin{array}{c}\text { Liquidus } \\
\left({ }^{\circ} \mathrm{C}\right)\end{array}$ \\
$\mathrm{B} 1900$ & 62.1 & 1218 & 1280 & 1361 \\
$\mathrm{Mo} / \mathrm{Ta}$ & 57.8 & 1158 & 1278 & 1372 \\
$\mathrm{IN738}$ & 44.8 & 1158 & 1242 & 1334 \\
$\mathrm{Mo} / \mathrm{W}$ & 42.0 & 1144 & 1248 & 1333 \\
$\mathrm{Mo} / \mathrm{Ta}$ & 41.7 & 1131 & 1228 & 1338 \\
$\mathrm{Mo} / \mathrm{Nb}$ & 41.8 & 1143 & 1248 & 1341 \\
\hline
\end{tabular}

The following observations were made from the results of this program:

1) The room temperature tensile tests indicate that $\mathrm{Ta}$ and $\mathrm{Nb}$ appear to be greater $\gamma_{\mathrm{APB}}$ strengtheners than Mo and $\mathrm{W}$. In addition, it appears that $\mathrm{Ta}$ and $\mathrm{Nb}$ are similar $\gamma_{\mathrm{APB}}$ strengtheners. $\gamma_{\mathrm{APB}}$ is the antiphase boundary energy which controls the flow stress of superalloys up to about $760^{\circ} \mathrm{C}$, at which temperature the strength decreases rapidly with increasing temperature (9). 
2) $\mathrm{Ta}$ and $\mathrm{Nb}$ are greater $\gamma^{\prime}$ formers than Mo and $\mathrm{W}$ as evidenced by the changes in the $\gamma^{\prime}$ solvus temperature and volume fraction. As a result, it can be seen from the creep/stress rupture data that $\mathrm{Ta}$ and $\mathrm{Nb}$ are important alloying elements in producing a more creep resistant alloy.

Table III. Gamma Prime/Gamma Partitioning Ratios

\begin{tabular}{crrrr}
\hline Alloy & $\underline{\text { Ta }}$ & $\underline{\mathrm{Nb}}$ & $\underline{\mathrm{W}}$ & $\underline{\mathrm{Mo}}$ \\
$\mathrm{B} 1900$ & 0.48 & - & - & 0.19 \\
$\mathrm{Mo} / \mathrm{Ta}$ & - & - & - & 0.47 \\
& & & & \\
$\mathrm{IN738}$ & 0.97 & 0.66 & 1.44 & 0.27 \\
$\mathrm{Mo} / \mathrm{W}$ & 2.08 & 0.42 & - & 0.41 \\
$\mathrm{Mo} / \mathrm{Ta}$ & - & 0.61 & 0.76 & 0.32 \\
$\mathrm{Mo} / \mathrm{Nb}$ & 2.12 & - & 0.59 & 0.45 \\
\hline
\end{tabular}

\begin{tabular}{|c|c|c|c|c|}
\hline Alloy & $\begin{array}{c}0.2 \% \\
\text { Yield Strength } \\
(\mathrm{MPa}) \\
\end{array}$ & $\begin{array}{c}\text { UTS } \\
\text { (MPa) }\end{array}$ & $\begin{array}{c}\text { Elongation } \\
(\%) \\
\end{array}$ & $\begin{array}{l}\text { RA } \\
(\%) \\
\end{array}$ \\
\hline B1900 & 756 & 993 & 12.4 & 18.7 \\
\hline $\mathrm{Mo} / \mathrm{Ta}$ & 667 & 800 & 9.0 & 15.7 \\
\hline IN738 & 879 & 1061 & 7.7 & 10.6 \\
\hline MoM & 894 & 1085 & 7.9 & 11.2 \\
\hline $\mathrm{Mo} / \mathrm{Ta}$ & 932 & 1031 & 3.3 & 11.5 \\
\hline $\mathrm{Mo} / \mathrm{Nb}$ & 847 & 1035 & 8.3 & 10.2 \\
\hline
\end{tabular}

3) Ta and $\mathrm{Nb}$ have a greater affinity to occupy Al sites in the $\gamma^{\prime}$ phase than Mo. This tentative conclusion is based on the sharp decreases in the $\gamma$ solvus temperature when Mo replaces the other refractory elements. The yield strength values are also consistent with this conclusion. 


\begin{tabular}{ccccc} 
Alloy & $\begin{array}{c}\text { Stress } \\
\text { (MPa) }\end{array}$ & $\begin{array}{c}\text { Minimum } \\
\text { Creep Rate } \\
\left(\times 10^{-8}\right)\end{array}$ & $\begin{array}{c}\text { Rupture } \\
\text { Life } \\
\text { (Hours) }\end{array}$ & $\begin{array}{c}\text { Elongation } \\
(\%)\end{array}$ \\
B1900 & 641.2 & 6.0 & 120.0 & 7.0 \\
$\mathrm{Mo} / \mathrm{Ta}$ & 641.2 & 26.7 & 40.5 & 11.4 \\
& & & & \\
$\mathrm{IN738}$ & 600 & 8.8 & 100.8 & 6.6 \\
$\mathrm{Mo} / \mathrm{W}$ & 600 & 44.3 & 42.0 & 14.9 \\
$\mathrm{Mo} / \mathrm{Ta}$ & 600 & 11.2 & 70.0 & 7.6 \\
$\mathrm{Mo} / \mathrm{Nb}$ & 600 & 11.1 & 72.0 & 6.4 \\
\hline
\end{tabular}

4) Ta is a greater MC-type carbide former than Mo and $\mathrm{Ti}$. When $\mathrm{Ta}$ was replaced in the $\mathrm{B} 1900$ alloy with $\mathrm{Mo}$, a semi-continuous $\mathrm{Mo}_{2} \mathrm{C}$ grain boundary carbide formed in the alloy. In addition, the concentration of $\mathrm{Ti}$ dramatically increased in the MC carbide phase when Ta was removed. This extra Ti was found to come from the strengthening $\gamma$ ' phase, which, in turn, caused a weakening of the alloy.

5) $\mathrm{Ta}$ and $\mathrm{Nb}$ were found to be more hot corrosion resistant than Mo in IN738 and $\mathrm{B} 1900$.

The role of refractory alloying elements in the iron-nickel base superalloy IN718

The presence of refractory elements in Inconel 718, as in nickel-base superalloys, increases the strength of the alloy's matrix and $\gamma^{\prime}$ phases $(10,11)$. In addition, the presence of $\mathrm{Nb}$ promotes the precipitation of an additional strengthening phase known as $\gamma^{\prime \prime}$. Gamma double-prime is a metastable, ordered, and coherent body-centered tetragonal $\mathrm{Ni}_{3} \mathrm{Nb}$ phase which precipitates either in the matrix or on $\gamma^{\prime}$ particles (12). It has been argued that most of the strength associated with this alloy results from the distortion of the matrix caused by this phase (13).

As mentioned, Inconel 718 , one of the most widely used superalloys in the jet engine industry, accounts for approximately $35 \%$ of all wrought superalloy production. IN718's exceptional fabricable and weldable properties, as well as its adequate strength at temperatures up to $650^{\circ} \mathrm{C}$, make this alloy a favorable material to use in the medium temperature regions of the jet turbine engine; e.g., the turbine disk and shaft. The alloy's high $\mathrm{Nb}$ content of approximately $5.3 \mathrm{wt} . \%$ also makes it a major consumer of $\mathrm{Nb}$. 
However, associated with these favorable attributes, IN718 possesses a problem which not only restricts its use to the medium and lower temperature regions of jet turbine engines, but also threatens its existence in many of the components in the next generation of high performance jet engines. The problem arises from overaging of the $\gamma^{\prime \prime}$ particles and the formation of a more stable, but needle-like, $\mathrm{Ni}_{3} \mathrm{Nb}(\delta)$ phase at the expense of the strengthening, but metastable, $\gamma^{\prime \prime}$ phase at elevated temperatures. It is believed that the high concentration of $\mathrm{Nb}$ in the alloy is responsible for the formation of this $\delta$ phase. Both reactions result in a degradation of the alloy's heat resistant mechanical properties $(14,15)$. In addition, the rates of these reactions increase with higher temperatures. This results in an operating ceiling temperature of about $650^{\circ} \mathrm{C}$, and a limited service lifetime for the IN718 component parts.

Recent advances in the jet engine industry are placing new demands for an alloy which exhibits the excellent fabricability and heat resistant properties of IN718, but which is not hampered by the alloy's relatively low temperature ceiling. Alternative nickel-base superalloys are currently being developed to satisfy these demands. This, in turn, would reduce the role of IN718 in these engines (16).

One of the problems with these new alloys, many of which are powder metallurgical systems, is their relatively high processing expense compared to IN718. Cleanliness associated with powder production and processing, as well as prior powder boundary problems are still of some concern with respect to $P / M$ superalloy uses. Therefore, the development of a more stable IN718-type alloy is still under active pursuit by many laboratories..

In order for IN718 to continue satisfying the requirements imposed by the superalloy industry, its composition must be modified for increased strength and thermal stability at higher temperatures. Adding more niobium will increase the strength by producing more $\gamma^{\prime \prime}$, yet it will also result in a decrease in thermal stability and lower the temperature ceiling for $\delta$.

Another argument entails adding more fcc elements ( $\mathrm{Ni}, \mathrm{Co}$ ) into the alloy. This may stabilize the $\gamma^{\prime \prime}$ (and prevent $\delta$ formation), but may not boost the mechanical properties at any temperature.

The most promising modification points toward varying the alloy chemistry in such a way as to increase the amount of the more stable $\gamma^{\prime}$ phase. Preliminary experimental results (17) suggest that allowing the atomic percent of aluminum and titanium to equal that of niobium may result in a more thermally stable $\gamma^{\prime \prime}$, due to the greater fraction of $\gamma^{\prime \prime}$ particles coarsening on $\gamma^{\prime}$. Increasing the amount of Al, and possibly $\mathrm{Ti}$, should result in more $\gamma^{\prime}$ and especially more $\gamma^{\prime}$ surface area for the $\gamma^{\prime \prime}$ to nucleate and grow. By increasing the number of $\gamma^{\prime \prime}$ nucleation sites, more $\gamma^{\prime \prime}$ particles should form. In doing so, this would produce finer sized $\gamma^{\prime \prime}$ particles upon reaching equilibrium, which could result in a reduction in the driving force to form $\delta$. 
In our research program, which is funded by The Niobium Products Company ( a subsidiary of Companhie Brasileira de Metallurgia e Mineracao [CBMM]), we chose to study the effects of modifying the alloy chemistry of IN718 following this latter approach. Three sets of alloys were produced, see Table VI. The first alloy series examines the effect of increasing the $(\mathrm{Al}+\mathrm{Ti}) / \mathrm{Nb}$ ratio by increasing the $\mathrm{Al}+\mathrm{Ti}$ content, while maintaining the niobium level at $5.25 \mathrm{wt}$. \%. The second alloy series compares the effects of $\mathrm{Al}$ and $\mathrm{Ti}$ on the stability of each phase by increasing the $\mathrm{Al} / \mathrm{Ti}$ ratio from 0.86 to 1.67 while maintaining the $(\mathrm{Al}+\mathrm{Ti}) / \mathrm{Nb}$ ratio and $\mathrm{Ti}$ content. The third set, which was produced after an intensive investigation of the first two sets, follows the strategy of the second series by increasing the Al/Ti ratio to 1.78; however, this series also studies the effect of reducing the Ti content in the alloy.

Table VI. Chemical Composition of the IN718-type Alloys (Wt\%)

\begin{tabular}{|c|c|c|c|c|c|c|c|c|c|}
\hline Alloy & Al & Ti & $\underline{\mathrm{Nb}}$ & $\underline{\mathrm{Ni}}$ & $\underline{\mathrm{Fe}}$ & Mo & Cr & $\frac{(A l+T i)}{N b}$ & $\frac{\mathrm{Al}}{\mathrm{Ti}}$ \\
\hline IN718-1 & 0.46 & 0.95 & 5.26 & bal & 18.25 & 3.05 & 18.00 & 0.65 & 0.86 \\
\hline 4 & 0.63 & 1.34 & 5.28 & bal & 18.30 & 3.05 & 17.80 & 0.90 & 0.83 \\
\hline 9 & 0.53 & 0.96 & 4.32 & bal & 18.30 & 3.02 & 18.15 & 0.85 & 0.98 \\
\hline 10 & 0.68 & 0.97 & 4.91 & bal & 18.30 & 3.03 & 18.10 & 0.86 & 1.24 \\
\hline 11 & 0.87 & 0.96 & 5.42 & bal & 18.00 & 3.02 & 17.80 & 0.90 & 1.61 \\
\hline 12 & 0.94 & 0.96 & 5.72 & bal & 17.83 & 3.05 & 17.53 & 0.89 & 1.74 \\
\hline 13 & 0.87 & 0.90 & 5.38 & bal & 18.05 & 3.04 & 17.80 & 0.88 & 1.72 \\
\hline 14 & 0.86 & 0.86 & 5.66 & bal & 17.95 & 3.06 & 17.70 & 0.82 & 1.78 \\
\hline
\end{tabular}

In what follows is an abbreviated summary of our results. More extensive results and discussion are published elsewhere $(18,19)$. Figure 1 shows the effect of these modifications on the transformation time for the $\delta$ phase. It can be seen that increasing the $(\mathrm{Al}+\mathrm{Ti}) / \mathrm{Nb}$ and $\mathrm{Al} / \mathrm{Ti}$ ratios in the alloy resulted in an increased time to form the embrittling $\delta$ phase. Table VII gives the lattice parameters of the $\gamma^{\prime}$ and $\gamma^{\prime \prime}$ phases, while Tables VIII and IX show their sizes and volume fractions following a 100 hour heat treatment at $760^{\circ} \mathrm{C}$. The effect of increasing these ratios also resulted in a greater misfit between the matrix and $\gamma^{\prime \prime}$ phase, which, in turn resulted in the smaller $\gamma^{\prime \prime}$ particles. On the other hand, the decrease in misfit between the matrix and $\gamma^{\prime}$ phase resulted in an increase the size of the more 
stable $\gamma$ particles. Table IX shows that increasing these ratios also produced more of the stable $\gamma^{\prime}$ compared to the metastable $\gamma^{\prime \prime}$ counterpart.

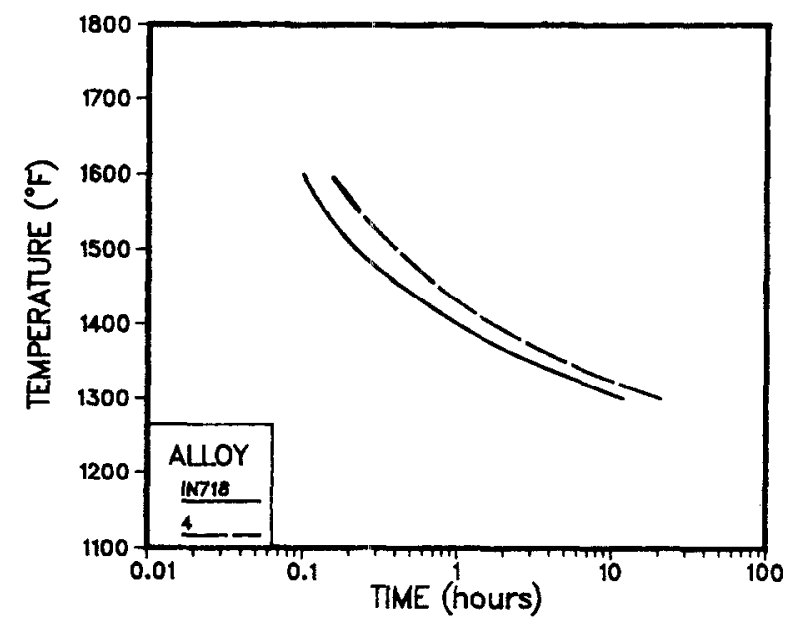

(a)

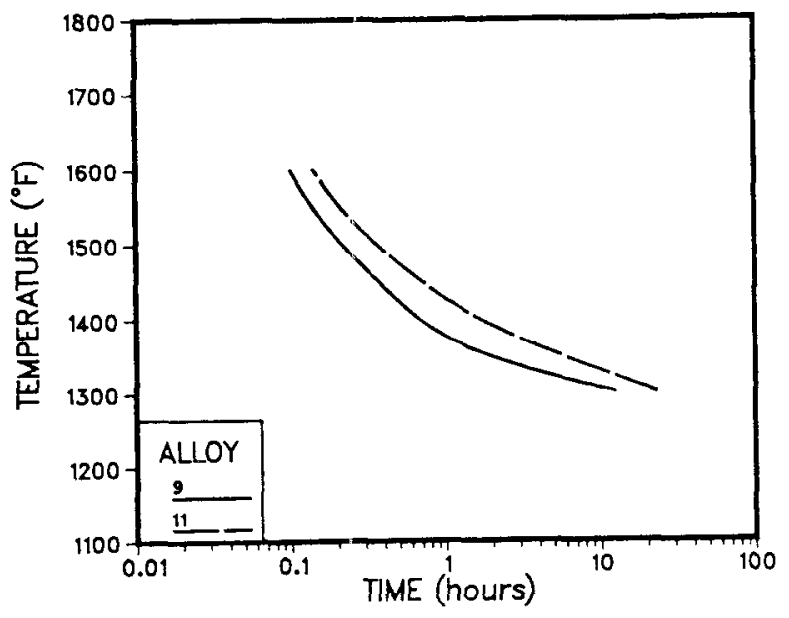

(b)

Figure 1. Time-Temperature-Transformation curves for alloys (a) 1 and 4 and (b) 9 and 11. 
Table VII. X-Ray Lattice Parameters of the matrix, $\gamma^{\prime}$, and $\gamma^{\prime \prime}$ phases (following $760^{\circ} \mathrm{C}-600 \mathrm{hr}$ heat treatment)

\begin{tabular}{rcccc} 
Alloy & $\begin{array}{c}\gamma \\
\text { a-axis } \\
(\AA)\end{array}$ & $\begin{array}{c}\gamma^{\prime} \\
\text { a-axis } \\
(\AA)\end{array}$ & $\begin{array}{c}(\AA) \\
\text { a-axis } \\
(\AA)\end{array}$ & $\begin{array}{c}\gamma^{\prime \prime} \\
\text { c-axis } \\
(\AA)\end{array}$ \\
4 & 3.6008 & 3.606 & 3.626 & 7.416 \\
9 & 3.5986 & 3.607 & 3.625 & 7.416 \\
10 & 3.5956 & 3.606 & 3.625 & 7.410 \\
11 & 3.5964 & 3.607 & 3.626 & 7.417 \\
12 & 3.6007 & 3.608 & 3.627 & 7.429 \\
13 & - & 3.606 & 3.625 & 7.422 \\
14 & - & 3.607 & 3.629 & 7.418 \\
\hline
\end{tabular}

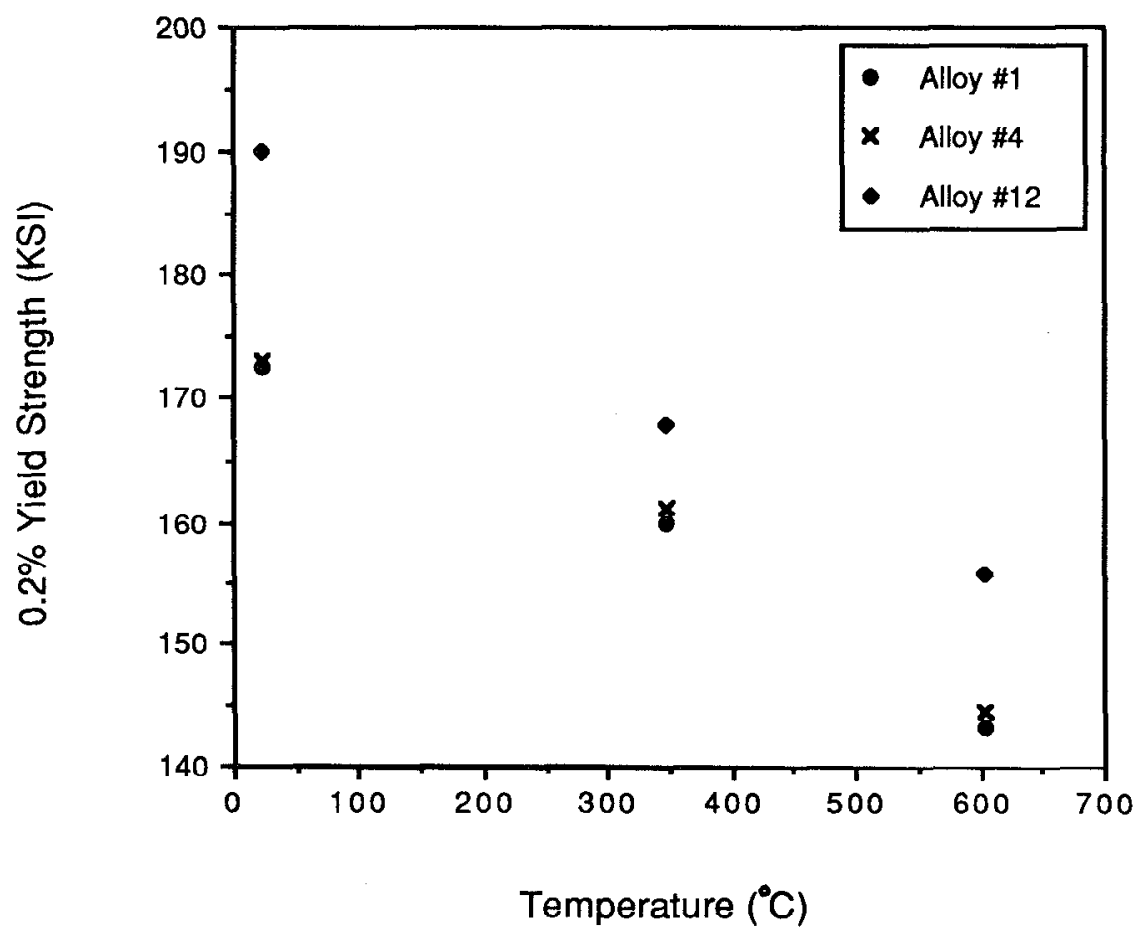

Figure 2. Room temperature and elevated temperature $0.2 \%$ yield strengths of alloys 1,4 , and 12 . 
Figure 2 shows the effect of these modification on the room temperature and elevated temperature tensile properties. The results from the abbreviated thermal stability test are given in Table $X$. In this test samples were creep/stress rupture tested a) in their initially heat treated condition and b) following an aging treatment at $732^{\circ} \mathrm{C}$ for 1000 hours, which was designed to overage the $\gamma^{\prime \prime}$ and force the formation of $\delta$ phase. Not only did these modifications produce a stronger alloy at ambient and elevated temperatures, but also resulted in a more thermally and microstructurally stable alloy, see Figure 3.

Table VIII. Average $\gamma$ and $\gamma^{\prime \prime}$ Precipitate Sizes After 100 Hour Heat Treatment at $760^{\circ} \mathrm{C}$

\begin{tabular}{|c|c|c|c|}
\hline & $\gamma^{\prime}$ & & \\
\hline Alloy & $\begin{array}{c}\text { Diameter } \\
(\mathrm{mm})\end{array}$ & $\begin{array}{l}\text { Length } \\
(\mathrm{mm})\end{array}$ & $\begin{array}{l}\text { Thickness } \\
\text { (mm) }\end{array}$ \\
\hline IN718-1 & 0.045 & 0.090 & 0.016 \\
\hline 4 & 0.048 & 0.064 & 0.011 \\
\hline 9 & 0.032 & 0.084 & 0.011 \\
\hline 10 & 0.044 & 0.065 & 0.008 \\
\hline 11 & 0.051 & 0.052 & 0.006 \\
\hline 12 & 0.052 & 0.048 & 0.006 \\
\hline 13 & 0.048 & 0.050 & - \\
\hline 14 & - & 0.048 & - \\
\hline
\end{tabular}

Table IX. $\gamma^{\prime}$ and $\gamma^{\prime \prime}$ Volume Fractions After 100 Hour Heat Treatment at $760^{\circ} \mathrm{C}$

$\begin{array}{rrr}\text { Alloy } & \begin{array}{c}\gamma^{\prime} \\ (\%)\end{array} & \begin{array}{r}\gamma^{\prime \prime} \\ \text { IN718-1 }\end{array} \\ 4 & 3.5 & 10.1 \\ 9 & 5.3 & 6.5 \\ 10 & - & - \\ 11 & 4.9 & 3.8 \\ 12 & 8.1 & 3.0 \\ & 9.1 & 2.6\end{array}$


(70 KSI)

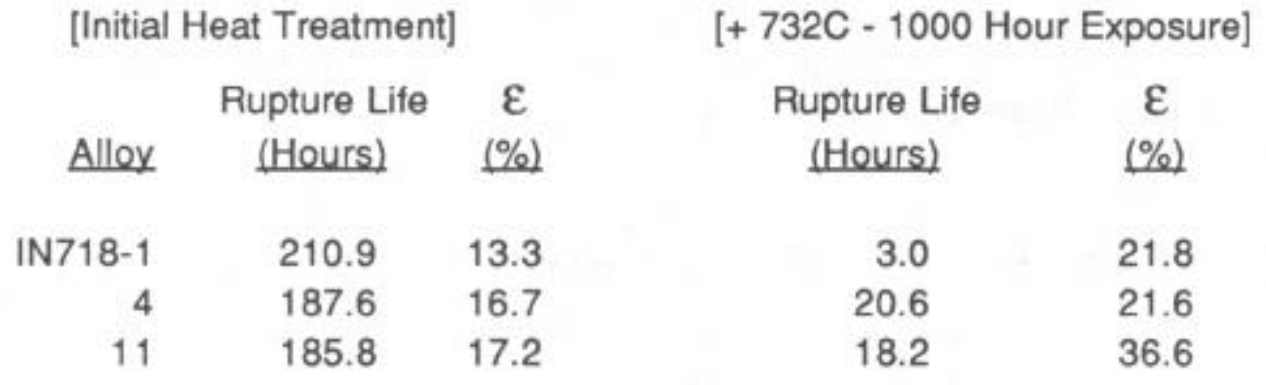

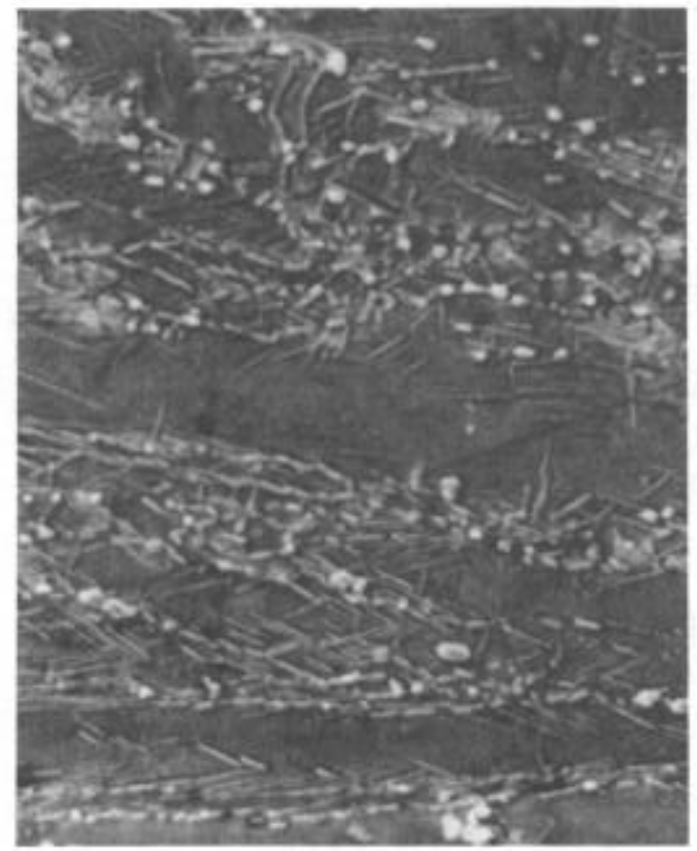

(a)

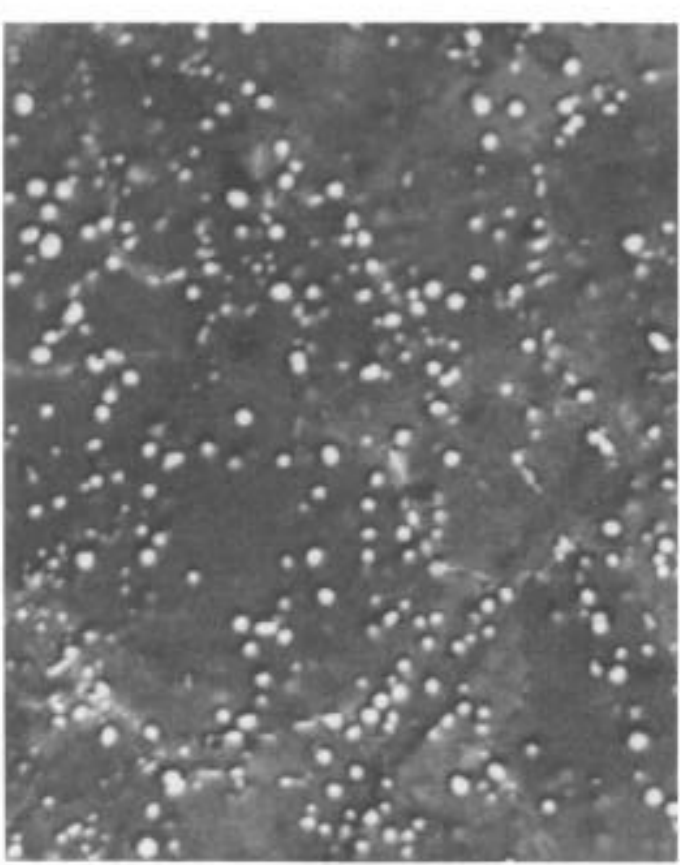

(b)

Figure 3. Scanning electron micrographs of alloys (a) 1, and (b) 11 after 1000 hour exposure at $732^{\circ} \mathrm{C}$.

These preliminary results indicate that increasing the $\mathrm{Al} / \mathrm{Ti}$ and/or the $\mathrm{Al}+\mathrm{Ti}$ content above that of the original IN718 results in a more thermally and 
mechanically stable alloy. I his could be due to the higher volume traction of $\gamma$, the smaller and more misfitting $\gamma^{\prime \prime}$ particles, and/or the reduced amount of $\delta$ in the alloy. These results also indicate that more of the high temperature heat resistant $\mathrm{Nb}$ can be added into the alloy without any corresponding loss in stability.

The second phase of this alloy design program, which is currently under way, will more extensively study the properties of a larger, commercial-sized ingot of the most stable alloy, alloy 12 . The results of this program, to date, indicate a promising future for IN718 in the jet turbine engines.

\section{Concluding remarks}

Refractory elements, in particular $\mathrm{Nb}$ and $\mathrm{Ta}$, are important alloying additions in nickel-base and iron-nickel-base superalloys. They are responsible for much of the strength associated with these heat resistant alloys. The work performed at Columbia University's Center for Strategic Materials shows the significance of $\mathrm{Nb}$ and $\mathrm{Ta}$ as alloying additions in current superalloys. In addition, these elements have been proven to be necessary additions in the design of future superalloys demanding greater strength and temperature resistance.

\section{Acknowledgements}

We would like to thank the Office of Naval Research (ONR) for their sponsorship (grant N-00014-83-K-0223) in studying the role of refractory elements in nickel-base superalloys. We thank Don Polk of the ONR for his interest and monitorship. We also thank the Niobium Products Company, which is a subsidiary of Companie Brasileira de Metallurgia e Mineracao (CBMM), for their sponsorship in developing a more thermally stable IN718-type alloy. In particular, we thank $\mathrm{Dr}$. Harry Stuart and E. A. Loria for their interest and monitorship. The material and mechanical working was made available by The Wyman-Gordon Company. We thank Steve Reichman and W. H. Couts for their technical advice. We also thank The Special Metals Corporation for casting the original ingots.

\section{References}

1. O.H. Kriege and J.M. Baris, Trans. ASM, 1969, vol. 62, pp. 195-200.

2. J.F. Barker, E.F. Ross and J.F. Radavich, Journal of Metals, Jan. 1970, pp. 31-41.

3. J.A. Ford and R.B. Herchenroeder, "Conservation and Substitution Technology for Critical Materials," NBS Publication NBSIR 82-2495, April 1982 , p. 23.

4. R.B. Herchenroeder, "A Review of Columbium and Tantalum for High 
Temperature Usage," Internal Report to Cabot Corporation, Mat.1981, 19 pages.

5. O.H. Kriege and J.M. Baris, Trans. ASM, Vol. 62, 1969, pp. 195-200.

6. M. Gull, D.N. Duhl and A.F. Giamei, Superalloys 1980, ASM, Metals Park, OH.,1980, pp. 205-14.

7. J.K. Tien, P.W. Keefe and J.P. Collier, "The Role of Refractory Elements in Nickel-Base Superalloys: An Overview," Refractory Alloying Elements in Superalloys, ASM Press, Metals Park, OH.,1984, pp. 1-14.

8. J.P. Collier. P.W. Keefe and J.K. Tien, Met. Trans. A, 1986, Vol 17A, pp. 651-61.

9. S. Purusothaman and J.K. Tien, Acta Met., 1978, Vol. 26, pp. 519-28.

10. J.K. Tien and S. Purushothaman, "Metallurgy of High Temperature Alloys," Properties of High Temperature Alloys, Electrochemical Society, Inc., Princeton, N.J., 1976, pp. 3-41.

11. R.F. Decker, "Strengthening Mechanisms in Nickel-Base Superalloys," Internal report for The International Nickel Company, Inc., 1969, 22 pages.

12. R. Cozar and A. Pineau, Met. Trans. A, 1973, Vol. 4, pp. 47-59.

13. J.M. Oblak, D.F. Paulonis, and D.S. Duvall, Met. Trans. A, 1974, Vol. 5, pp. 143-153.

14. D.F. Paulonis, J.M. Oblak and D.S. Duvall, Trans. ASM, 1969, Vol. 62., pp. 611-622.

15. R.S. Cremisio, H.M. Butler and J.F. Radavich, Journal of Metals, Nov.1969, pp. 55-61.

16. R.H. Caless and D.F. Paulonis, "Development of Gatorized Merl 76 for Gas Turbine Disk Applications, Superalloys 1988, ASM, Metals Park, OH.1988.

17. R. Cozar and A. Pineau, Met. Trans. A, 1973, Vol. 4, pp. 47-59.

18. J.P. Collier, S.H. Wong, J.C. Phillips and J.K.Tien, Met. Trans. A, 1988, Vol 19A, pp. 1657-66.

19. J.P. Collier, A.O. Selius and J.K. Tien, "On Developing a Microstructurally and Thermally Stable Iron-Nickel Base Superalloy," Superalloys 1988, ASM, Metals Park, OH. 1988. 